\title{
Papers
}

\section{Multicentre controlled trial of parenting groups for childhood antisocial behaviour in clinical practice}

\author{
Stephen Scott, Quentin Spender, Moira Doolan, Brian Jacobs, Helen Aspland
}

\begin{abstract}
Objective To see whether a behaviourally based group parenting programme, delivered in regular clinical practice, is an effective treatment for antisocial behaviour in children.

Design Controlled trial with permuted block design with allocation by date of referral.

Setting Four local child and adolescent mental health services.

Participants 141 children aged 3-8 years referred with antisocial behaviour and allocated to parenting groups (90) or waiting list control (51).

Intervention Webster-Stratton basic videotape programme administered to parents of six to eight children over 13-16 weeks. This programme emphasises engagement with parental emotions, rehearsal of behavioural strategies, and parental understanding of its scientific rationale.

Main outcome measures Semistructured parent interview and questionnaires about antisocial behaviour in children administered 5-7 months after entering trial; direct observation of parent-child interaction.

Results Referred children were highly antisocial (above the 97th centile on interview measure). Children in the intervention group showed a large reduction in antisocial behaviour; those in the waiting list group did not change (effect size between groups $1.06 \mathrm{SD}$ (95\% confidence interval 0.71 to 1.41$)$, $\mathrm{P}<0.001)$. Parents in the intervention group increased the proportion of praise to ineffective commands they gave their children threefold, while control parents reduced it by a third (effect size between groups 0.76 ( 0.16 to 1.36$), \mathrm{P}=0.018)$. If the 31 children lost to follow up were included in an intention to treat analysis the effect size on antisocial behaviour was reduced by $16 \%$.

Conclusions Parenting groups effectively reduce serious antisocial behaviour in children in real life conditions. Follow up is needed to see if the children's poor prognosis is improved and criminality prevented.
\end{abstract}

\section{Introduction}

Aggression and fighting are part of normal child development and can help children to assert and defend themselves. Persistent, poorly controlled antiso- cial behaviour, however, is socially handicapping and often leads to poor adjustment in adults. ${ }^{1}$ It occurs in $5 \%$ of children, ${ }^{2}$ and its prevalence is rising. ${ }^{3}$ The children live with high levels of criticism and hostility from their parents and are often rejected by their peers. ${ }^{3}$ Truancy is common, most leave school with no qualifications, and over a third become recurrent juvenile offenders. ${ }^{4}$ In adulthood, offending usually continues, relationships are limited and unsatisfactory, and the employment pattern is poor. The long term public cost from childhood for individuals with this behaviour is up to ten times higher than for controls and involves many agencies. ${ }^{5}$

Antisocial behaviour accounts for 30-40\% of referrals to child mental health services. ${ }^{6}$ Most referrals meet general clinical diagnostic guidelines for conduct disorder from ICD-10 (international classification of diseases, 10th revision), which require at least one type of antisocial behaviour to be marked and persistent. Rather fewer meet the diagnostic criteria for research, which for the oppositional defiant type of conduct disorder seen in younger children require at least four specific behaviours to be present. ${ }^{7}$ The early onset pattern-typically beginning at the age of 2 or 3 years-is associated with comorbid psychopathology such as hyperactivity and emotional problems, language disorders, neuropsychological deficits such as poor attention and lower IQ, high heritability, ${ }^{8}$ and lifelong antisocial behaviour. ${ }^{9}$ In contrast, teenage onset antisocial behaviour is not associated with other disorders or neuropsychological deficits, is more environmentally determined than inherited, and tends not to persist into adulthood. ${ }^{9}$

Harsh, inconsistent parenting is strongly associated with antisocial behaviour in children, ${ }^{4}$ but whether this is a cause or consequence or is due to a common genetic predisposition has been less clear. ${ }^{3}$ The pioneering work of Patterson and colleagues showed that parents had a causal role in maintaining antisocial behaviour by giving it attention and in extinguishing desirable behaviour by ignoring it. ${ }^{10}$ This led to behaviourally based training interventions for parents, which have been shown to be effective in many studies in the United States. ${ }^{11}$

Most trials of parenting programmes have been carried out in specialised university research clinics by the team who invented the treatment, who are highly motivated, extensively trained, and deal only with anti-

\author{
Institute of \\ Psychiatry, King's \\ College London, \\ London SE5 8AF \\ Stephen Scott \\ senior lecturer in child \\ and adolescent \\ psychiatry \\ Moira Doolan \\ research family \\ therapist \\ Helen Aspland \\ psychologist \\ St George's \\ Hospital, Medical \\ School, London \\ SW17 0RE \\ Quentin Spender \\ senior lecturer in child \\ and adolescent \\ psychiatry \\ Maudsley Hospital, \\ London SE5 8AZ \\ Brian Jacobs \\ consultant child and \\ adolescent psychiatrist \\ Correspondence to: \\ S Scott \\ s.scott@iop.kcl.ac.uk
}

BMJ 2001;323:1-7 
social behaviour. Many trials used volunteers or people selected by referrers as willing to take part in parenting projects, thus excluding many disorganised, unmotivated, or disadvantaged families, who have the most antisocial children. ${ }^{2}$ A review of meta-analyses of published trials of psychological treatments for childhood disorders found that in university settings the effect size was large, from 0.71 to $0.84 \mathrm{SD}^{12}$ In contrast, a review of six studies of outcome in regular service clinics since 1950 showed no significant effects, ${ }^{12}$ and a large trial offering unrestricted access to outpatient services found no improvement. ${ }^{13}$ Reasons suggested for the poor outcome in clinic cases include that they have more severe problems, come from more distressed families, and receive less empirically supported interventions from staff with heavier caseloads. Some have concluded that though child psychotherapy works, the bad news is that it doesn't in real life. The true picture may be even less encouraging as none of the clinic trials included an intention to treat analysis.

As far as we are aware there has been no substantial controlled trial of parenting programmes or any other treatment for antisocial behaviour in Europe. We investigated whether a behaviourally based parenting programme would be effective in everyday NHS practice, with standard referrals to child mental health services and regular clinic staff to carry out the intervention. Our hypothesis was that children whose parents received management training would become less antisocial than those whose parents received no such training.

\section{Methods}

Protocol

Study population-The trial took place from 1995-9 in four NHS child and adolescent mental health services: Croydon, Brixton/Belgrave/Camberwell, St George's (all south London); Chichester (West Sussex). The relevant ethics committees approved the project. Eligible children were all those aged 3 to 8 years who were referred for antisocial behaviour to their local multidisciplinary child and adolescent mental health service. Exclusion criteria were clinically apparent major developmental delay, hyperkinetic syndrome, or any other condition requiring separate treatment. Parents had to be able to understand English and attend at group times. Written consent was obtained.

Intervention-We used the basic videotape parent training programme developed by Webster-Stratton. ${ }^{14}$ This has proved highly successful in trials from the university parenting clinic of its originator. ${ }^{15}$ Voices were dubbed into English accents. The parents of six to eight children were seen as a group for two hours each week over 13-16 weeks; the children did not take part, and no other treatment was given. The programme covered play, praise and rewards, limit setting, and handling misbehaviour. In each session, two group leaders showed videotaped scenes of parents and children together, which depict "right" and "wrong" ways of handling children. Parents discussed their own child's behaviour and were supported while they practised alternative ways of managing it. Each week tasks were set for parents to practise at home and telephone calls made to encourage progress. Therapists held regular jobs in their local service, came from a range of

\section{Intervention programme}

Content

- Structured sequence of topics, introduced with video clips of parents with children

- Topics include play, praise, incentives, setting limits, and discipline

- Emphasis on promoting sociable, self reliant child behaviour, and calm parenting

- Constant reference to parent's own experience and predicament

- Theoretical basis informed by extensive empirical research and made explicit

- Detailed manual available to ensure treatment fidelity and to enable replicability

Delivery

- Collaborative approach acknowledging parents' feelings and beliefs

- Difficulties normalised, humour and fun encouraged

- Parents supported to practise new approaches during session and through homework

- Written feedback from parents after every session

- Creche, good quality refreshments, and transport provided

- Group leaders supervised weekly to ensure treatment fidelity and to develop skills, using videotape of last session to rehearse therapeutic approach

disciplines, and were trained over three months. Intervention sessions were videotaped, and weekly supervision meetings were held to ensure adherence to the manual. ${ }^{14}$

Measures were taken from mothers on entry to the trial and after completion of the intervention or waiting list period, five to seven months later. They included demographic details, six measures of child behaviour, and one of parent behaviour. We used the parent account of child symptoms interview as the primary outcome measure for antisocial behaviour. This well validated semistructured interview uses investigator based criteria to assess the frequency and severity of antisocial behaviours such as fighting, destruction, and disobedience; scores are strongly predictive of later psychosocial outcome. ${ }^{16}$ The $\kappa$ inter-rater reliability statistic on 20 randomly selected interviews was 0.84 for the conduct problems scale, 0.81 for the hyperactivity scale, and 0.76 for the emotional problems scale. We also used the strengths and difficulties questionnaire $(\mathrm{SDQ})^{17}$ and the child behaviour checklist. ${ }^{18}$ In the parent defined problems questionnaire, the parent lists the three problems they would most like to see changed and indicates the severity of each on a $10 \mathrm{~cm}$ line labelled "not a problem" at one end and "couldn't be worse" at the other. The parent daily report questionnaire records 36 behaviours as present or absent each day for a week. ${ }^{19}$ This measure is widely used as an alternative to prolonged direct observation in the home by an independent observer. A diagnosis of conduct disorder (oppositional defiant type) was made if ICD-10 research criteria were met at interview. ${ }^{7}$ Finally, parents were directly observed. An 18 minute structured play task ${ }^{20}$ was given to the mother and child at home and videotaped. We randomly selected 20 cases, which an assessor blind to their status coded using a manual..$^{21}$ The assessor 
counted parental praise and inappropriate commands and combined them to give a ratio. Intraclass correlation coefficients were 0.96 and 0.97 , respectively.

Calculation of sample size-We designed the trial to detect a minimum important difference in effect size of $0.6 \mathrm{SD}$ on the primary outcome measure. To be detected with $80 \%$ power at $\alpha=0.05$, with a $2: 1$ allocation ratio, this would require groups of 68 and 34 (total 102).

Analysis strategy - We use analysis of variance over time, covarying for age and sex, to test for an interaction between time and arm of trial. We analysed all allocated cases for which we had follow up data, irrespective of how much intervention was received. We also carried out an intention to treat analysis, in which we analysed data from all allocated cases, including those lost to follow up, for which we assumed there was no change since first assessment.

\section{Assignment}

In each centre we allocated participants to intervention or control (waiting list) using a permuted block design. ${ }^{22}$ Each block consisted of a consecutive three month period, during which all eligible referrals were allocated to one arm of the trial. This design was chosen with the aim of recruiting at least six cases per parenting group, with the assumption that 5-15 cases were referred in each block. Allocation was determined by date of receipt of referral letter. Participants in the control arm were offered treatment after completion of the trial.

The planned overall ratio of intervention to control blocks was 2:1. Each centre had to have at least two intervention blocks per year to ensure that there were enough cases to run a group even after any drop outs. Also, intervention blocks had to be more than three months apart to ensure there were sufficient cases to run a group within six months of a child being assessed. Therefore we determined the sequence nonrandomly for each centre annually in advance with the advice of a statistician. This gave 52 blocks: 35 intervention and 17 control (ratio 2.06:1). The sequence was kept in a locked cabinet.

\section{Masking}

Parents were blind to allocation at the initial assessment; interviews were carried out by researchers blind to the duration or sequence of blocks. Follow up assessments were carried out by a different researcher to avoid the parent giving socially desirable responses, but blinding at this stage was often not possible as parents talked about treatment.

\section{Results}

Participants-The figure shows participant flow and follow up. No parents of a child allocated to the waiting list received a parenting programme, and no parents of a child allocated to the parenting group were returned to the waiting list. No child received psychotropic medication. Table 1 gives characteristics of the referred children. Compared with population norms, mean scores were above the 97th centile for conduct problems, above the 90th centile for hyperactivity, and above the 78th centile for emotional problems. There were no significant differences between groups. Table 2 gives details of family characteristics; most were poor

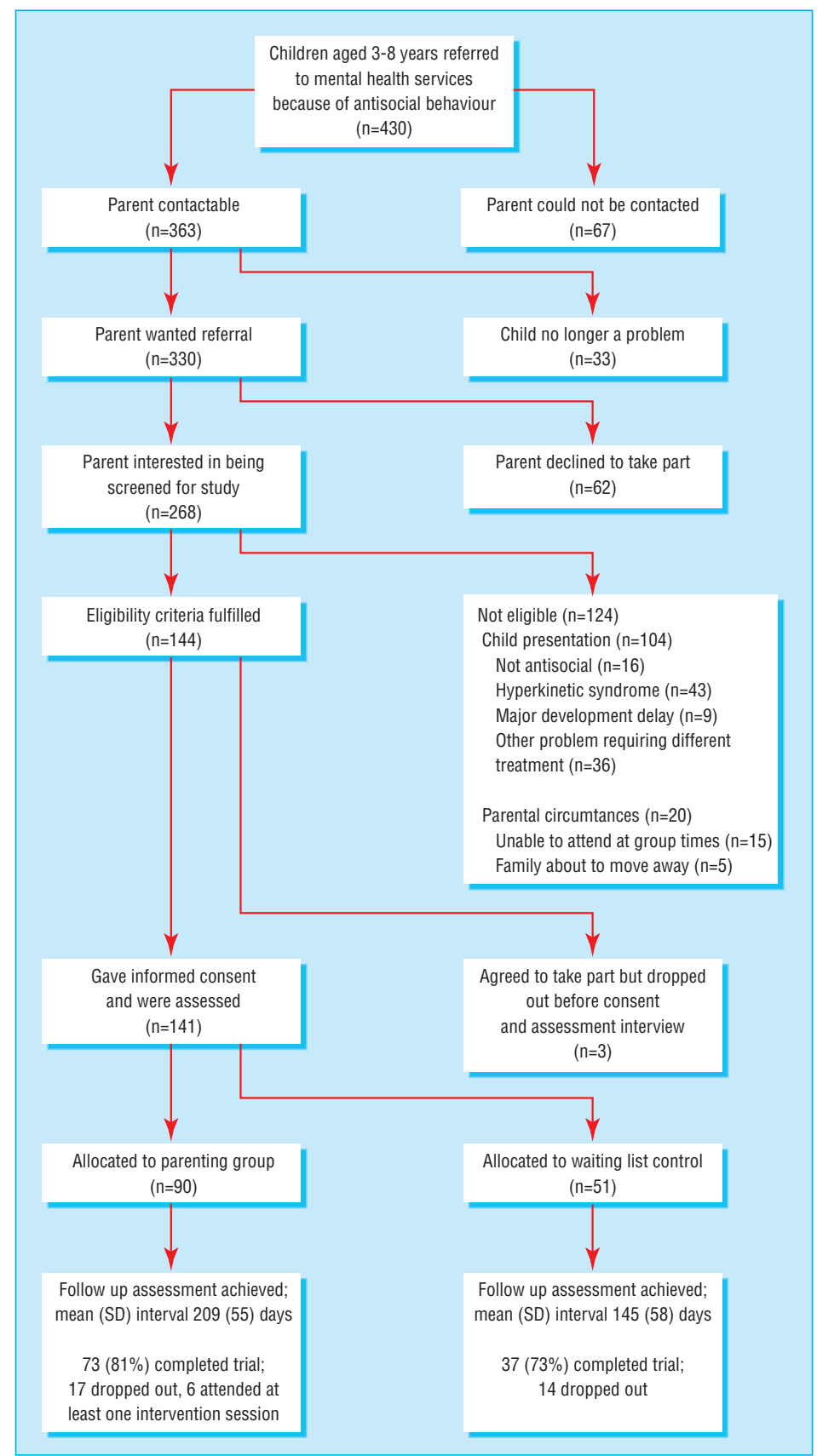

Participant flow and follow up

and disadvantaged. There were no significant differences between groups.

Programme attendance and cost-The mean attendance was 9.1 (SD 4.2) sessions. Thirteen (18\%) of the 73 families attended four or fewer times, which we consider dropping out, and $60(82 \%)$ attended five or more, which we consider reasonable compliance. The programme cost $£ 571$ per child compared with $£ 563$ for usual individual treatment of six sessions, calculated with standard economic methods. ${ }^{5}$

Child behaviour-Table 3 gives results on the outcome measures from the semistucured interview. For antisocial behaviour, control children showed no change and intervention children showed a large improvement. A similar picture was seen on all other outcome measures. Parentally defined problems in the 
Table 1 Characteristics of children referred for antisocial behaviour*

\begin{tabular}{lcccc} 
& Parenting groups $(\mathbf{n}=\mathbf{7 3})$ & Waiting list controls $(\mathbf{n}=\mathbf{3 7})$ & Lost to follow up (n=31) & Not in trial $(\mathbf{n}=\mathbf{2 8 9}) \dagger$ \\
\hline No (\%) of boys & $52(71)$ & $27(73)$ & $25(81)$ & $216(75)$ \\
\hline Mean (SD) age (years) & $5.45(1.57)$ & $5.97(1.72)$ & $5.81(1.37)$ & $5.67(1.54)$ \\
\hline Mean (SD) interview scores: & & & & \\
\hline Conduct problems & $1.59(0.45)$ & $1.53(0.42)$ & $1.60(0.42)$ & - \\
\hline Hyperactivity & $1.23(0.70)$ & $1.13(0.65)$ & $1.07(0.60)$ & - \\
\hline Emotional problems & $0.76(0.60)$ & $0.69(0.37)$ & $0.72(0.49)$ & - \\
\hline
\end{tabular}

*Groups did not differ significantly on any characteristic, with $\chi^{2}$ test for sex and analysis of variance for other variables.

†Of 430 referrals, 67 families could not be contacted, 33 said they no longer had problems, 62 declined to take part, 124 did not fulfil criteria for eligibility, and three dropped out before consent or assessment.

Table 2 Characteristics of families in study with children with antisocial behaviour (number (percentage)) ${ }^{\star}$ and all families in United Kingdom

\begin{tabular}{|c|c|c|c|c|}
\hline & $\begin{array}{c}\text { Parenting group } \\
(\mathrm{n}=73)\end{array}$ & $\begin{array}{l}\text { Waiting list controls } \\
\quad(n=37)\end{array}$ & $\begin{array}{l}\text { Lost to follow up } \\
\qquad(\mathrm{n}=31)\end{array}$ & $\begin{array}{c}\text { Mean values for UK } \\
(\%) \dagger\end{array}$ \\
\hline Lone parent & $30 / 67(45)$ & $14 / 36(39)$ & $12 / 27(44)$ & 7 \\
\hline Parent in ethnic minority & $13 / 64(20)$ & $4 / 31(13)$ & $5 / 23(22)$ & 9 \\
\hline Mother left school by 16 & $34 / 67(51)$ & $20 / 35(57)$ & $21 / 27(61)$ & 13 \\
\hline Council or housing association home & $34 / 73(47)$ & $19 / 35(54)$ & $11 / 27(41)$ & 17 \\
\hline No car & $30 / 73(41)$ & $16 / 36(44)$ & $11 / 28(39)$ & 28 \\
\hline Child eligible for free school meals & $34 / 69(49)$ & $17 / 34(50)$ & $15 / 28(54)$ & 18 \\
\hline Total weekly household income $\leqslant £ 175$ & $14 / 63(22)$ & $10 / 30(28)$ & $6 / 26(23)$ & 5 \\
\hline
\end{tabular}

Denominators vary owing to missing data.

*Groups within the study did not differ significantly on any characteristic with $\chi^{2}$ test.

†Data from Social Trends London: Office of National Statistics, 2000.

child included hitting people, running away, and fighting with sibling. Intention to treat analysis reduced the effect size by $16 \%$ on the primary outcome measure (antisocial behaviour) and by $-6 \%$ to $36 \%$ (mean 22\%) on the secondary measures. Symptoms of hyperactivity reduced significantly, as did overall emotional and behaviour problems.

Clinical significance-The mean initial score for conduct problem on interview was above the 97 th centile on population means, well into the clinical range. After intervention it fell to below the 82nd centile, within the normal range. However, $21 \%$ of children in the intervention group failed to improve by at least $0.3 \mathrm{SD}$, and a third still met research criteria for oppositional defiant disorder.

Parental behaviour-The ratio of praise to inappropriate commands increased threefold in the intervention group but fell by a third in the controls (table 3 ).

\section{Discussion}

The children recruited to this study were initially behaving in a highly aggressive and antisocial way; many were also hyperactive and had emotional

Table 3 Child and parent behaviour outcomes after parent had attended parenting group

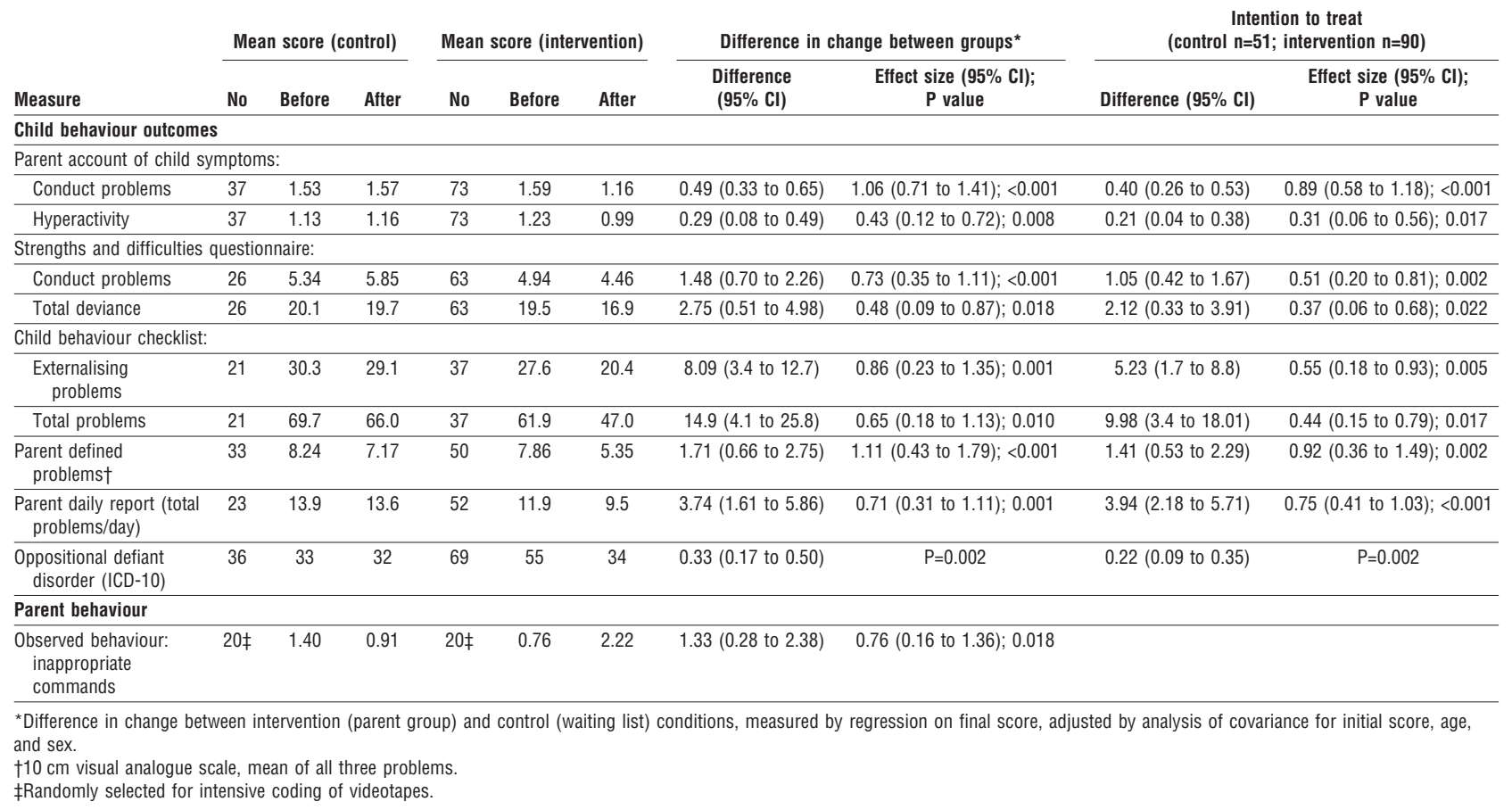




\section{What is already known on this topic}

Children who persistently display a high level of antisocial behaviour are at high risk of social rejection, juvenile delinquency, and long term unemployment; the cost to society is high

While some behaviourally based parenting programmes have been shown to be effective in university centre trials with volunteers or specially selected cases, most trials of psychological treatments for children in real life settings have shown no effect

\section{What this study adds}

An evidence based intervention is available for use in regular clinical practice that effectively reduces antisocial behaviour in referred children

The intervention works well with children at risk of criminality from a combination of highly antisocial behaviour, multiple psychopathology, and social deprivation

problems. Most lived in deprived circumstances and were at high risk of later juvenile delinquency and social exclusion. The children of parents allocated to parenting groups showed a large reduction in antisocial behaviour, but those in the control group did not improve. After the intervention, parents were giving their children far more praise to encourage desirable behaviour and more effective commands to obtain compliance. Attendance at parenting groups was good, despite the population being notoriously hard to engage.

\section{Methodological considerations}

Sequential block designs can lead to biased allocation. Referrers, clinic staff, and parents might all have tried to influence allocation. However, at the time of referral, referrers did not know of the existence of the trial and were unaware of duration or sequence of blocks. Clinic staff and parents were unaware of the duration and sequence of blocks, and parents were not informed of allocation until after the first assessment. ${ }^{4}$ Our trial incorporated several features to avoid this bias, and there was no evidence that groups differed. Effects were shown across three different measurement perspectives: parental perception, investigator based criteria, and direct observation. No measure was taken of child behaviour in school as there was no intervention in this setting. Planned future studies include a follow up to see whether the improvements persist and a comparison with usual clinic treatment.

\section{Implications for services}

This intervention is an effective, evidence based treatment for antisocial behaviour in children in real life conditions. It works well with disadvantaged families and costs no more than conventional treatment. Groups could be delivered in community settings rather than in mental health services to reduce stigma and increase accessibility. ${ }^{23}$ However, parenting groups should not automatically be offered as the only intervention for antisocial behaviour. Careful assessment of children is necessary as a proportion (a third in this trial) have coexistent psychiatric diagnoses, such as the hyperkinetic syndrome, post-traumatic stress disorder, and encopresis, that require additional treatment. Such children were excluded from this trial only because the additional treatment would have made it hard to interpret which intervention was changing antisocial behaviour. We believe that in most cases parent training would be a beneficial and easily combined treatment.

Our results are likely to be related to the programme chosen and its implementation. This programme coherently combines behavioural principles with sympathetic support and other features shown in the literature to enhance effectiveness. ${ }^{24}$ Implementation was by personable, committed staff given adequate training and regular supervision to promote treatment fidelity. ${ }^{25}$ Such parenting programmes are only just beginning to become available in the United Kingdom. They show promise as a cost effective way to reduce the personal and economic burden of antisocial behaviour in children and to prevent criminality and social exclusion.

We thank all participating parents, clinic staff, and intervention staff for their help; Jenny Price for data collection; Drs Byrne, Dare, Fitzpatrick, Nikapota, Subotsky, Warren, and Weeramanthri for arranging access to families; Professor Graham Dunn for advice on design and statistics, and Professor WebsterStratton for advice and encouragement on the intervention.

Contributors. SS initiated the research, was the principal investigator, was responsible for the design and execution of the study, coordinated with clinicians, managed the St George's site, trained the researchers to use the measures, developed the observational coding scheme, participated in data interpretation, and wrote the paper. QS carried out the statistical analysis, managed the Chichester site, participated in data collection, and contributed key ideas. MD managed and participated in the data collection, managed the south London sites, and contributed core ideas. BJ helped to plan and run the project and contributed ideas to evaluation and intervention strategies. HA developed the coding scheme, rated the videotapes, and participated in data collection. SS and QS are guarantors.

Funding: NHS Research and Development Executive; Sussex Weald and Downs NHS Trust. SS received a Wellcome research training fellowship during the first year.

Competing interests: None declared

1 Scott S. Aggressive behaviour in childhood. BMJ 1998;316:202-6

2 Meltzer H, Gatward R, Goodman R, Ford T. The mental health of children and adolescents in Great Britain. London: Office of National Statistics, 2000.

3 Rutter M, Hagell A, Giller H. Antisocial behaviour by young people. Cambridge: Cambridge University Press, 1998.

4 Farrington DP. The development of offending and antisocial behaviour from childhood: key findings from the Cambridge study in delinquent development.J Child Psychol Psychiatry 1995;36:929-64.

5 Scott S, Knapp M, Henderson J, Maughan B. Financial cost of social exclusion: follow up study of antisocial children into adulthood. $B M J$ 2001;323:191-4

6 Audit Commission. Children in mind. London: Audit Commission, 1999.

7 World Health Organization The ICD-10 classification of mental and behavioural disorders-diagnostic criteria for research. Geneva: World Health Organization, 1993

8 Silberg J, Meyer J, Pickles A, Simonoff E, Eaves L, Hewitt J, et al Heterogeneity among juvenile antisocial behaviours: findings from the criminal and antisocial behaviour. London: Wiley, 1996.

9 Moffitt T. Adolescence-limited and life-course-persistent antisocial behaviour: a developmental taxonomy. Psychol Rev 1993;100:674-701.

10 Patterson GR. Coercive family process. Eugene, OR: Castalia, 1982.

11 Kazdin AE. Parent management training: evidence, outcomes, and issues. JAm Acad Child Adol Psychiatry 1997;36:10-8.

12 Weisz J, Weiss B, Donenberg GR. The lab versus the clinic: effects of child and adolescent psychotherapy. Am Psychol 1992;47:1578-85.

13 Andrade AR, Lambert WL, Bickman L. Dose effect in child psychotherapy: outcomes associated with negligble treatment. JAm Acad Child Adol Psychiatry 2000;39:161-8.

14 Webster-Stratton C, Hancock L. Training for parents of young children with conduct problems: content, methods, and therapeutic processes. In: Briesmeister JM, Schaefer CE, eds. Handbook of parent training. 2nd ed. New York: Wiley, 1998. 
15 Webster-Stratton C, Hollinsworth T, Kolpacoff M. The long-term effectiveness and clinical significance of three cost-effective training programs for families with conduct-problem children.J Consult Clin Psychol 1989;57:550-3.

16 Taylor E, Chadwick O, Heptinstall E, Danckaerts M. Hyperactivity and conduct problems as risk factors for adolescent development. J Am Acad Child Adolesc Psychiatry 1996;35:1213-26.

17 Goodman R. The strengths and difficulties questionnaire. J Child Psychol Psychiatry 1997;38:581-6.

18 Achenbach T M. Manual for the child behavior checklist 4-18. Burlington, VT: University Associates in Psychiatry, 1991.

19 Chamberlain P, Reid JB. Parent observation and report of child symptoms. Behavioral Assessment 1987;9:97-109.

20 Conduct Problems Prevention Research Group. Initial impact of the fast track prevention trial for conduct problems: 1 , The high risk sample. $J$ Consult Clin Psychol 1999;67:631-47.
21 Aspland H. The assessment of parent-child interactions in children with conduct problems: an evaluation of structured direct observation. London: Institute of Psychiatry, University of London, 2001 (MPhil thesis).

22 Altman DG. Practical statistics for medical research London: Chapman and Hall, 1982.

23 Scott S. Parenting programmes. In: Rutter M, Taylor E, eds. Child and adolescent psychiatry. 4th ed. Oxford: Blackwell Science (in press).

24 Webster-Stratton C. Preventing conduct problems in Head Start children: strengthening parenting competencies. J Consult Clin Psychol 1998;66:715-30.

25 Henggeler SW, Melton GB, Brondino MJ, Schere DG, Hanley JH. Multisystemic therapy with violent and chronic juvenile offenders and their families: the role of treatment fidelity in successful dissemination. J Consult Clin Psychol 1997;65:821-33.

(Accepted 15 March 2001) 


\title{
Commentary: nipping conduct problems in the bud
}

\author{
Carolyn Webster-Stratton
}

The study by Scott et al adds to a growing body of evidence that early interventions with parents can prevent later antisocial behaviour by their children. It is also one of the few studies that evaluates an evidence based mental health intervention for conduct problems in a "real world" setting.

Several risk factors for later development of substance abuse, violence, or delinquency can be identified at a young age. Children at highest risk for later problems include those who start early with high rates of conduct problems, including oppositional defiant, aggressive, and antisocial behaviours. ${ }^{1}$ Children who have conduct problems at a young age are three times more likely to have serious and chronic violent careers than those who begin antisocial behaviour later. ${ }^{2}$ The risk of developing later antisocial problems is further increased if early onset conduct problems are combined with harsh and inconsistent parenting, low parental monitoring, and low parental involvement in school. ${ }^{3}$ If these early risk factors are not prevented or treated children may develop a cascading set of secondary risk factors, including academic failure, social exclusion, school drop out, and membership of deviant peer groups, which, in turn, accelerate their risk for future violence. ${ }^{4}$

Thus it is important to nip in the bud the earliest risk factors. Eron et al concluded that without early family treatment, aggressive behaviour in children "crystallises" by the age of 8 , making future learning and behavioural problems less responsive to treatment and more likely to become chronic. ${ }^{5}$ Yet recent projections suggest that fewer than $10 \%$ of young children who need treatment for conduct problems ever receive it, ${ }^{6}$ and an even smaller percentage receive empirically validated treatments. Many programmes for conduct disorders and violence prevention are available, but few have evidence based validation from well designed trials in diverse populations and settings. This failure to provide evidence is short sighted and may seriously undermine public confidence in crime prevention efforts.

Scott et al's is the second randomised controlled clinical trial by an independent team confirming the effectiveness of a particular parenting approach for young children diagnosed with oppositional defiant disorder and conduct disorder. ${ }^{7}$ They showed a reduction in two major risk factors for future antisocial behaviour: aggressive behaviour in children under the age of 8 and critical and harsh parenting.

This study helps narrow the gulf between the science and practice of mental health-psychosocial treatments. This study is one of the few that evaluates an evidence based mental health intervention for conduct problems in an existing mental health agency. ${ }^{8}$ The results provide valuable information about this treatment programme's replicability and effectiveness in a setting with a diverse cultural and socioeconomic population.

The results attest to the motivation and capability of a population of socioeconomically disadvantaged mothers to benefit from a fairly brief parenting programme. Eighty per cent of the families attended at least half of the group based sessions, and parent satisfaction was high. This is no small accomplishment for families with young children struggling under stressful economic conditions to meet basic food and housing needs. This study's success with families often characterised unfairly as dysfunctional or unmotivated contradicts these characterisations. Although the Incredible Years Parenting Program is a prescribed therapeutic programme, with detailed manuals and session protocols, its ultimate success depends on skilled therapists tailoring it to families' individual needs.

An additional interesting finding was that hyperactive symptoms were also significantly reduced. We have also recently noted that children with conduct problems who also show inattentive and hyperactive symptoms respond as well to parent training as children without hyperactive symptoms (RR Hartmann, et al, unpublished). Taken together these two studies suggest that children who are comorbid for oppositional defiant and conduct disorder and hyperactive and inattentive symptoms benefit from parent training.

Parenting programmes might be even more cost effective, more pervasive in impact, and less stigmatising if they were offered as a preventive measure before children were socially excluded and diagnosed as having oppositional defiant disorder or conduct disorder. This could be accomplished by making programmes available for parents of young children through nurseries and primary schools or for teenagers in secondary school. Evaluating the impact of immunising all families against future development of conduct problems by providing comprehensive parent education programmes and a child social emotional curriculum for everyone are key goals for the next generation of research. Additionally we need studies to establish the link between reducing targeted family and child risk factors early in life and a decrease in later violence, crime, and drug misuse.

CWS is the developer of the Incredible Years Parenting Program, which was evaluated by Scott et al in their study, and disseminates the program to therapists and thus stands to gain from a favourable review.

1 Patterson GR, DeGarmo DS, Knutson N. Hyperactive and antisocia behaviors: comorbid or two points in the same process? Dev Psychopatho 2000;12:91-106.

2 Loeber R, Farrington DP. Young children who commit crime: epidemiology, developmental origins, risk factors, early interventions, and policy implications. Dev Psychopathol 2000;12:737-62.

3 Patterson G, Reid J, Dishion T. Antisocial boys: a social interactional approach. Eugene, OR: Castalia Publishing; 1992.

4 Hawkins JD, Catalano RF, Kosterman R, Abbott R, Hill KG. Preventing adolescent health-risk behaviors by strengthening protection during childhood. Arch Ped Adolesc Med 1999;153:226-34.

5 Eron LD, Huesmann LR, Zelli A. The role of parental variables in the learning of aggression. In: Pepler DJ, Rubin KH, editors. The development and treatment of childhood

6 Kazdin AE. Conduct disorders in childhood and adolescence. Thousand Oaks, CA: Sage Publications, 1995

7 Taylor TK, Schmidt F, Pepler D, Hodgins H. A comparison of eclectic treatment with Webster-Stratton's Parents and Children Series in a Children's Mental Health Center: A randomized controlled trial. Behavio Therapy 1998;29:221-40.

8 Chambless DL, Hollon SD. Defining empirically supported therapies. J Consulting Clin Psychol 1998;66:7-18.
Parenting Research Clinic, School of

Nursing, University of Washington, Seattle, WA 98195 , USA

professor and director 